\title{
Retrograde Synaptic Communication Via Gap Junctions Coupling Auditory Afferents to the Mauthner Cell
}

\author{
Alberto E. Pereda, Theodore D. Bell, and Donald S. Faber \\ Department of Anatomy and Neurobiology, Medical College of Pennsylvania and Hahnemann University, \\ Philadelphia, Pennsylvania 19129
}

Large myelinated club endings of the goldfish eighth nerve arise in the sacculus and establish mixed electrotonic and chemical synapses with the distal part of the Mauthner (M-) cell's lateral dendrite. We show here, using paired pre- and postsynaptic recordings, that depolarizing currents generated postsynaptically (specifically, the mixed synaptic potential produced by activation of part of the afferent population) can in some cases excite the presynaptic fibers and cause them to backfire. Strikingly, while in some systems junctional properties prevent the antidromic spread of depolarizing currents, physiological properties of these afferents and the gap junctions promote backfiring: the amplitude of the coupling potential recorded from an afferent fiber is voltage dependent, increasing with depolarization and being reduced during hyperpolarization. Two mechanisms, with different kinetics, underlie this voltage dependence. One, a nonlinear membrane property of the afferent fiber itself, enhances the coupling potential as the afferent membrane depolarizes. The second mechanism, which is less sensitive to voltage and is symmetric about the resting potential, most likely represents voltage dependence of the junctional membrane. Additionally, we also show retrograde diffusion of low molecular weight substances, as the fluorescent dye Lucifer yellow and the tracer Neurobiotin were found in the terminals of afferent fibers after being injected postsynaptically into the M-cell. These results suggest that the gap junctions in these primary afferents are not only involved in fast anterograde synaptic transmission but also provide the substrate for a retrograde intercellular communication. The electrical coupling may modify the input-output relation between eighth nerve afferents and the lateral dendrite by synchronizing the population of already active fibers and by promoting the recruitment of new fibers via backfiring, such that weaker inputs produce relatively larger responses.

[Key words: gap junctions, Mauthner cell, synaptic plasticity, retrograde communication, dye coupling, electrical synapses]

\footnotetext{
Received Dec. 14, 1994; revised May 1, 1995; accepted May 8, 1995

This work was supported in part by National Institute of Health Grant NS15335. We thank P. Mollard and D. Baird for their contributions to the Lucifer yellow experiments, and M. Volaski for software design and computer support.

Correspondence should be addressed to Alberto E. Pereda, Department of Anatomy and Ncurobiology, Mcdical College of Pcnnsylvania and Hahncmann University, 3200 Henry Avenue, Philadelphia, PA 19129.

Copyright (C) 1995 Society for Neuroscience $0270-6474 / 95 / 155943-13 \$ 05.00 / 0$
}

Electrotonic transmission generally has its anatomical substrate in the gap junction plaque, which is a cluster of intercellular channels that allows the passage of electrical currents and small metabolites (Bennett et al., 1991). The passive spread of electrical currents through this junction synchronizes the activity of various nerve cell groups, such as the oculomotor neurons of telenst fish (Kriehel, 1969; Korn and Bennett, 1975). It also provides a means for lateral integration of signals in another set of homologous cells, namely retinal horizontal cells (Wu, 1994). Finally, in many instances electrotonic synapses couple heterologous nerve cells, one example being the contacts between primary vestibular and spinal afferents and their target second order neurons in lower vertebrates (Korn and Faber, 1979). They often coexist in these systems with chemical junctions, thercby forming mixed synapses (Shapovalov, 1980). The main function of the electrotonic synapses at these contacts presumably is the effective fast transmission of sensory information from one cell to the next. Although, in analogy with some invertebrate systems (Furshpan and Potter, 1959), rectification of electrotonic coupling has been reported (Auerbach and Bennett, 1969; Ringham, 1975), these synapses generally transmit bidirectionally, and the passive spread of postsynaptic depolarization may even lead to backfiring of the presynaptic cell (Zipser and Bennctt, 1976; Korn et al. 1977; Slesinger and Bell, 1985).

One such group of afferents are the "large myelinated cluh endings" of the goldfish eighth nerve (Nakajima, 1974). Their parent axons originate in the sacculus and run in the posterior branch of the nerve, and each one establishes a single mixed contact with the distal part of the Mauthner (M-) cell lateral dendrite (Tuttle et al., 1986; Lin and Faber, 1988). Gap junctions have never been observed between presynaptic endings (Nakajima, 1974). Orthodromic coupling between axons in the posterior branch of the eighth nerve and the lateral dendrite (Furshpan, 1964) is considered to be functionally relevant since the startle reflex mediated by the M-cell (Eaton et al., 1991) requires speed. The electrotonic junctions at these large myelinated club endings are electrically bidirectional (Furshpan, 1964), in that coupling potentials are recorded in afferents when the dendrite is depolarized (for example by the M-cell antidromic action potential). Consequently a previous report based on measurements of coupling coefficients and DC transfer resistances concluded that this electrical synapse does not rectify (Lin and Faber, 1988a).

Since the orthodromic synaptic coupling potential and the chemical postsynaptic potential evoked by the synchronous activation of many of these fibers can be at least as large as the antidromic action potential when recorded in the M-cell's lateral 
dendrite we considered the possibility that the retrograde spread of this dendritic signal can affect presynaptic excitability, such that activity in part of the afferent pool would influence the remainder. In this system, the distal dendrite is within a few hundred micrometers from the lateral edge of the brain and the distance between the nerve and the hair cells is only a few millimeters. Since axons that terminate as large club endings have diameters of $5-15 \mu \mathrm{m}$, potentials generated at the dendrite should be detected in the sacculus (see Lin and Faber. 1988b). albeit smaller in amplitude. Also, since dye coupling has not previously been reported for these junctions we asked if substances injected postsynaptically can retrogradely reach the presynaptic terminals. The results presented here demonstrate that these contacts exhibit retrograde dye and electrical coupling with the M-cell, and that the latter can cause backfiring of the afferents. Moreover, in contrast with other systems, we also show that intrinsic properties of the junctional and nonjunctional membranes both favor this process. The junctional rectification described here is the opposite of that originally postulated to protect inactive eighth nerve fibers from being excited by dendritic depolarizations (Bennett et al., 1967). From a functional perspective, the spread of postsynaptically originated currents and backfiring might serve to enhance the effectiveness of eighth nerve input by adding a nonlinearity to the population inputoutput relationship, one that acts to synchronize the afferents and to hoost their postsynaptic effect.

\section{Materials and Methods}

For this study, 38 goldfish (Carassius auratus) $8-15 \mathrm{~cm}$ long were perfused through the mouth with cold tap water and immobilized with $d$-tubocurarine injected intranuscularly ( $1-3$ mo/gm body weight). The surgical and recording techniques used were similar to those described previously (Furshpan and Furukawa, 1962; Faber and Korn, 1978), although in this case the head was rotated laterally in order to directly visualize the entry into the brain of the posterior eighth nerve, which contains the large saccular fibers (Lin and Faber, 1988a).

Single fiber or simultaneous pre- and postsynaptic (see Fig. 1A), intracellular current-clamp recordings were obtained, using an Axoclamp 2-A amplifier (Axon Instruments). Individual eighth nerve afferents were penetrated either intracranially in the proximity of the Mauthner cell's lateral dendrite or, more often, outside the brain close to the point of entry of the nerve into the medulla. Electrodes were filled with a 2.5 $\mathrm{M} \mathrm{KCl}$ solution, and their resistances ranged between 10 and $35 \mathrm{M} \Omega$ Fibers projecting to the M-cell could be identified by the presence of electrotonic coupling potentials when the M-cell, antidronnic spike was evoked by stimulating the spinal cord (Fig. $1 \mathrm{~A}, \mathrm{Cl}$ ). When simultaneous recordings were performed, the second electrode $(2.5 \mathrm{M} \mathrm{KCl}, 4-12 \mathrm{M} \Omega$ ) was in the M-cell lateral dendrite, $250-300 \mu \mathrm{m}$ from the axon cap of the cell. Finally, a bipolar electrode placed on the posterior eighth nerve distal to the recording site (Fig. $1 A$ ) was used to stimulate a population of eighth nerve fibers.

Experimental data were recorded on tape (PCM data recorder, Vetter Instruments, Model 400) for subsequent off-line computer analysis using a Macintosh Quadra 950 computer equipped with National Instruments A-D boards and software developed in the laboratory (sampling interval $10-50 \mu \mathrm{sec}$ ). Student's $t$ test was used to assess statistical sig nificance of the obtained data.

For those experiments where dye coupling was investigated, the recording electrode was filled eilher with a 5\% solution of Lucifer yellow (lithium salt, Bioprobes, in distilled water), or a $4 \%$ solution of Neurobiotin [ $\mathrm{N}$-(2-(aminoethyl) biotinamide hydrochloride, Vector, in $2.5 \mathrm{M}$ $\mathrm{KCl}, 10 \mathrm{~mm}$ HEPES, $\mathrm{pH} 7.2$ ] and these solutions were pressure injected into the M-cell. The fish was then perfused intracardially with $4 \%$ paraformaldehyde in phosphate buffer $(0.12 \mathrm{M}$ at $\mathrm{pH}$ 7.4) for $15 \mathrm{~min}$, kept overnight in phosphate-buffered saline (PBS), and sectioned with a vibratome $(100 \mu \mathrm{m})$. In the case of the Lucifer yellow, the sections were mounted on slides and examined under fluorescent optical and confocal (Bio-Rad) microscopes, using an excitation wavelength of $488 \mathrm{~nm}$. In the case of Neurobiotin, these sections were rinsed several times with
PBS, then incubated with the Vectastain ABC reagent (Vector Laboratories) for $2 \mathrm{hr}$, rinsed again several times with PBS, and then reacted with $\mathrm{DAB}$ and $\mathrm{H}_{2} \mathrm{O}_{2}$ for $5 \mathrm{~min}$ to visualize the injected neurons. The sections were then mounted on gelatin coated slides, dehydrated, cleared, and covered.

\section{Results}

The data reported here were obtained during 53 intracellular recordings from eighth nerve afferents, either alone or while simultaneously recording from the M-cell's lateral dendrite. Resting potential and action potential averaged $-70.4 \mathrm{mV}$ $( \pm 0.99 \mathrm{mV}, \mathrm{SEM}, n=50)$ and $77.7 \mathrm{mV}( \pm 2.8 \mathrm{mV}, \mathrm{SEM}, n=$ 41 ), respectively. Most of these recordings were obtained in the posterior eighth nerve; when the recording site was instead at the level of the terminals near the lateral dendrite the major distinction was that the action potential amplitude was less (36 $\pm 0.72 \mathrm{mV}$ ). Single large myelinated club endings mediate mixed, electrical and chemical, transmission with the M-cell. This property is illustrated with the simultaneous pre- and postsynaptic recordings of Figure $1 B$, where two sequential presynaptic spikes triggered by a depolarizing current pulse evoked unitary synaptic potentials in the lateral dendrite. The first spike only produced an electrotonic response while the second coupling potential was followed by a chemically mediated EPSP, as described by Lin and Faber (1988a). Electrical coupling between the eighth nerve fibers and the lateral dendrite exhibits electrical bidirectionality, in that responses that originate postsynaptically can evoke antidromic or retrograde coupling potentials in the afferent fibers. This is the case for the M-cell's antidromic spike (Fig. 1C1). As shown in Figure $1 C 2$, the mixed synaptic response evoked by a weak stimulus to the posterior eighth nerve consists of a fast electrotonic or electric component followed by a chemical glutamatergic synaptic potential. The figure also shows that the response appears as a coupling potential (8th coup) in an afferent for which the stimulus strength is subthreshold. In this case, the recording site was in the brain and the terminal action potential was about $40 \mathrm{mV}$ in amplitude. In contrast, in Figure $1 B$ the presynaptic electrode was outside the brain and the spike was about $80 \mathrm{mV}$. Furthermore, the anti- and orthodromic coupling potentials in $\mathrm{C} 1, \mathrm{C} 2$ are greater than those typically determined with the presynaptic electrode more distant from the dendrite, that is, in the nerve (Lin and Faber, 1988a). This difference was consistently found, and it suggests the space constant of the fibers is shorter than assumed previously.

\section{Backfiring of individual afferents}

Strong stimuli to the posterior eighth nerve can evoke large synaptic responses in the lateral dendrite, where these contacts are closely segregated, with the electrical component being as large as $40 \mathrm{mV}$ in amplitude. We therefore tested the hypothesis that the spread of this dendritic depolarization to afferents not brought to threshold by the eighth nerve stimulation can cause backfiring. We first checked that a large coupling potential produced by 8 th nerve stimulation could directly evoke a spike in the recorded fibers $(n=18$ ). In the example of Figure 2, the eighth nerve stimulus strength was adjusted so that the amplitude of the evoked coupling potential was near the threshold of the recorded fiber, and this coupling potential sometimes produced an action potential or a fluctuating local response in the fiber (Fig. 2A). The latter could be detected even though the recording site was in the nerve. Second, the role of postsynaptic depolarizations in producing backfiring was even more clearly demonstrated when a weaker coupling potential evoked by the 

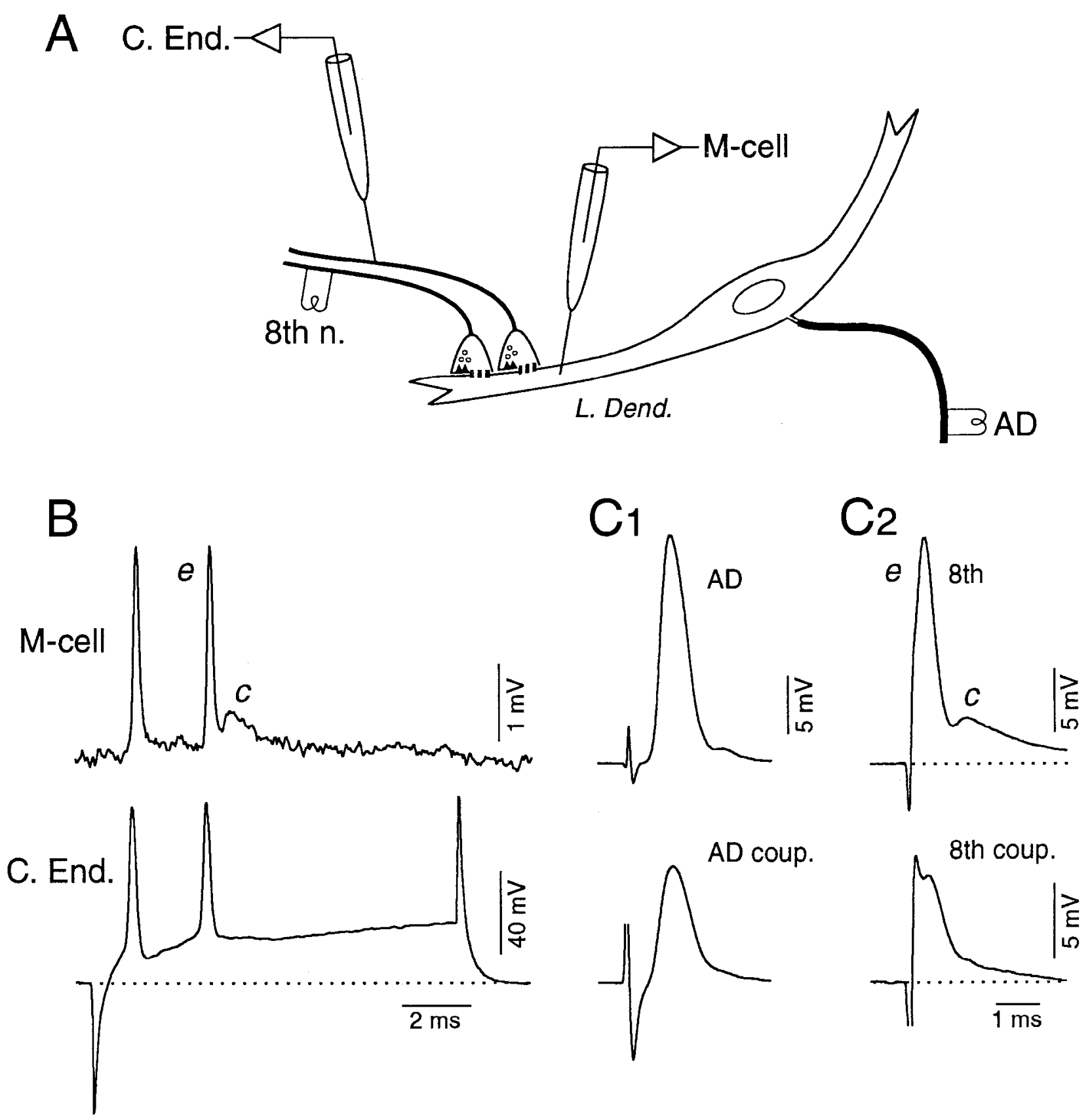

Figure 1. Bidirectional electrical transmission at eighth nerve fibers. $A$, Experimental arrangement. Intracellular recordings were obtained from the afferent fibers $(C$. End.) alone or while recording simultaneously from the Mauthner $(M-)$ cell's lateral dendrite $(L$. Dend.). Stimulating electrodes were placed on the posterior eighth nerve $(8 t h n$.) and the spinal cord $(A D)$. Afferents are shown as having mixed synapses with the dendrite. $B$, Mixed synaptic transmission demonstrated at the unitary level. Simultaneous recording from a single afferent (lower) in the nerve and the M-cell's lateral dendrite (upper). Presynaptic depolarization produced two actions potentials and corresponding postsynaptic potentials. While the first response shows only the electrical component the second response exhibits both electrical $(e)$ or electrotonic and chemical $(c)$ components. $C$, Electrotonic transmission between eighth nerve fibers and the M-cell is bidirectional, as demonstrated by successive intracellular pre- and postsynaptic recordings. In this case the presynaptic recording site was in the brain. $C l$, The antidromic $(A D)$ spike of the $\mathrm{M}$-cell (upper) is recorded as a coupling potential $(A D$ coup.) from the fiber (lower). This coupling potential was typically used for fiber identification. $C 2$, Stimulation of the posterior branch of the eighth nerve evokes a mixed excitatory response in the M-cell's lateral dendrite, with a fast electrotonic component ( $e$ ) and delayed chemical (c) response, as a result of activation of a population of afferent fibers. This response can also be recorded as a reverse coupling potential ( 8 th coup.) from a presynaptic fiber which is not directly excited by for the eighth nerve stimulus.

eighth nerve stimulus was paired with a second coupling potential, that produced by antidromic stimulation of the M-cell's axon (traces 1 and 2, respectively, in Fig. $2 B$, recording site in the brain). The amplitude of this last coupling potential was about $7 \mathrm{mV}$, and when it was timed to occur at the peak of the subthreshold depolarization produced by the weak eighth nerve stimulus, the two summed to evoke a presynaptic spike (Fig. $2 B$ ). Thus, depolarization of the M-cell lateral dendrite can cause backfiring of the afferent fibers.

This result raises the possibility that the activity of part of the 

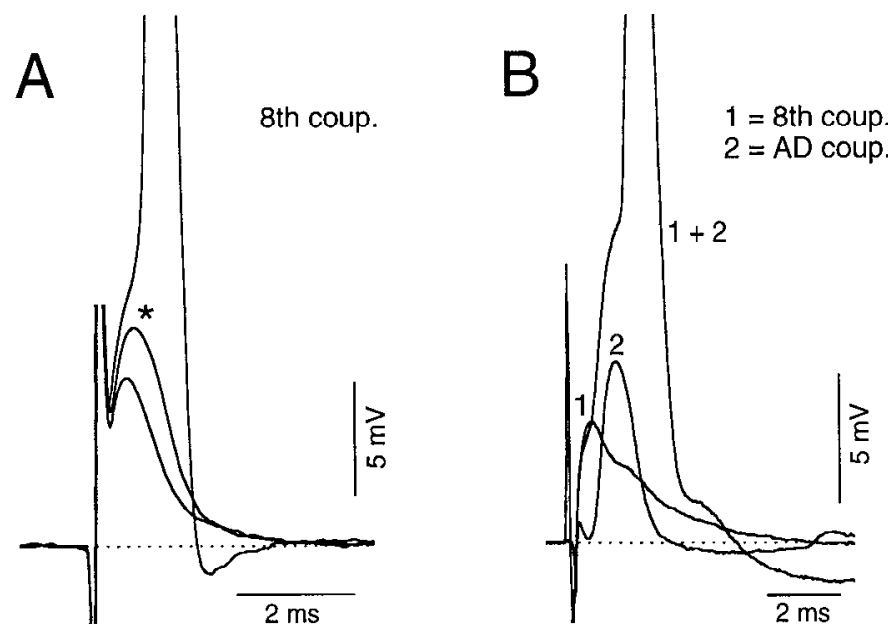

Figure 2. Retrograde coupling from the M-cell to single afferents contributes to backfiring. $A$, Eighth nerve induced potentials ( 8 th coup.) recorded from an afferent within the nerve and for which the stimulus strength was subthreshold. The coupling potential occasionally evoked either an active local response $(*)$ or a full-sized spike (shown at high gain with its peak truncated, actual spike height $=72 \mathrm{mV}$ ). $B$, Backfiring can be induced by pairing the coupling potentials produced by eighth nerve and antidromic stimulations. In another experiment, with the recording site in the medulla, the weakest response $(1=8$ th coup.) was evoked by eighth nerve stimulation and is a coupling potential relayed through the $\mathrm{M}$-cell. Antidromic stimulation also produced a subthreshold coupling potential $(2=$ AD coup.) in the M-cell, and when the two stimuli were paired $(1+2)$ a full sized spike $(52 \mathrm{mV})$ was triggered in the afferent. In both cases the superimposed traces represent averages of six or more consecutive individual responses.

afferent population can influence the excitability of the rest, suggesting a functional role for retrograde electrical coupling. Evidence for such a role is provided in Figure $3 A$, where the posterior eighth nerve was stimulated at two different strengths; strength 1 ( $\mathrm{S} 1$ ) evoked a large EPSP in the M-cell and an early spike in the recorded fiber, while a weaker strength (S2) pro- duced a smaller synaptic response and a delayed presynaptic spike. We suspect that while the highest strength stimulus directly activated the afferent, this was not the case for the weaker stimulus; rather, in that situation the coupling potential relayed through the M-cell to the afferent may have contributed to the initiation of the longer latency impulse in the fiber. Additional support for this idea comes from the observation that the M-cell response to eighth nerve stimulation occasionally exhibits small spike-like potentials superimposed on the chemically mediated EPSP, with their amplitudes and time course resembling those of the orthodromic unitary coupling potentials (Fig. $3 \mathrm{Bl}$ ). These "spikelets," probably signaling the backfiring of one or more afferents, are smaller in amplitude than the antidromic action potential recorded in the dendrite (Fig. 3B2), and they most likely are not local dendritic responses since this region of the cell apparently does not support any regenerative response (Faber and Korn, 1978; Faber and Korn, 1986).

\section{Voltage dependence of the coupling potential}

To test whether specific properties of the fibers or gap junctions might contribute to this backfiring, we examined the voltage dependence of the antidromic (AD) coupling potential recorded in a single 8th nerve afferent. For this purpose the AD coupling potential was paired with presynaptic depolarizing currents (Fig 4). The $\mathrm{AD}$ coupling potential was used instead of that produced by activating other 8 th nerve afferents in order to avoid possible complications due to local responses produced by changes in axonal excitability following direct stimulation of the nerve. This pairing procedure could also evoke backfiring, as shown in Figure $4 A$ for a presynaptic depolarizing current of $0.6 \mathrm{nA}$. Interestingly, the amplitude of the coupling potential was enhanced by depolarizing the fiber (Fig. $4 A$ ). This voltage dependence was present in all fibers studied, and it is also illustrated in the experiment of Figure $4 B$, where the antidromic coupling potential increased in amplitude as the afferent was depolarized by a 1 $\mathrm{nA}$ current pulse while it was reduced by hyperpolarizing the fiber. In this case the amplitude changes were +45.9 and
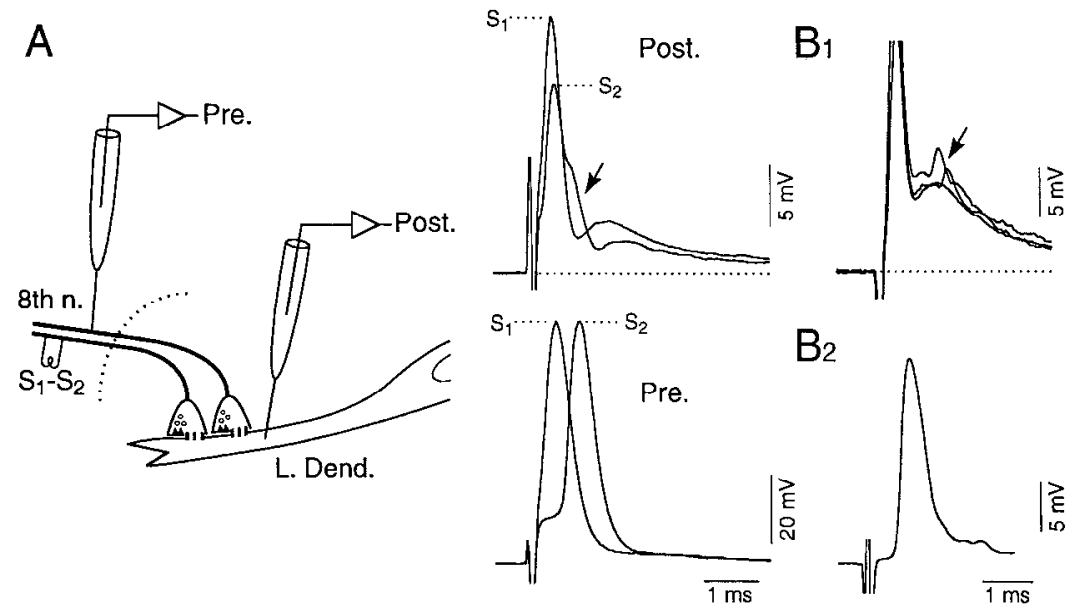

Figure 3. Indirect manifestation of backfiring in afferent fibers. A, Antidromic coupling can synchronize afferent impulse activity. I eft, Diagram indicating the presynaptic (Pre.) recording electrode was in the nerve outside the brain (delimited by dotted lines in this and subsequent figures) while the postsynaptic (Post.) one was in the lateral dendrite. Right, Simultaneously recorded pre- and postsynaptic responses to posterior eighth nerve stimulation at two different strengths $(S 1, S 2)$. The stronger stimulus evoked a large synaptic response in the $M$ cell and a short latency spike in the afferent $(S I)$, while S2 evoked a smaller synaptic response and a delayed spike in the fiber. Arrow, Indicates the coupling artifact associated with this spike on the falling phase of the electrotonic component of the postsynaptic response. $B I$ and $B 2$, Results from another experiment with dendritic recordings, supporting the concept of backfiring. BI, Superimposed records of "spikelets" (arrow) in the M-cell fulluwing ant eighth nerve response evoked by a strong stimulus. $B 2$, The larger M-cell antidromic spike recorded at the same dendritic location. 

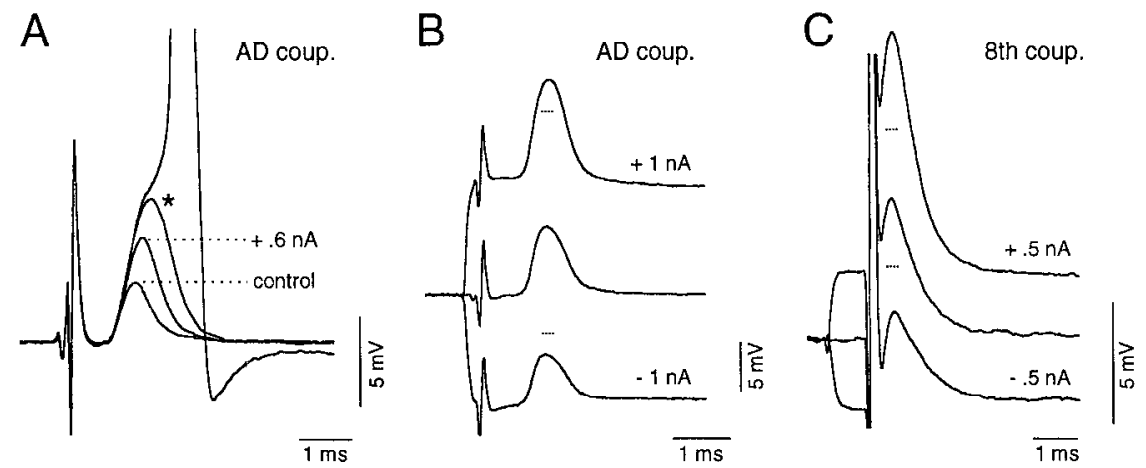

Figure 4. Electrotonic coupling from the M-cell to eighth nerve afferents is voltage dependent. $A-C$, Averaged recordings of coupling potentials in afferents during presynaptic polarization. $A$, Superimposed traces of the antidromic coupling potential observed at resting potential (control) and during the application of a steady $0.6 \mathrm{nA}$ depolarizing current. The coupling potential amplitude increases with depolarization and may evoke either a local active response $(*)$ or a presynaptic action potential. $B$, Another example, demonstrating that the coupling potential amplitude not only increases with depolarization (upper) but also decreases during hyperpolarization (lower trace). In this case current pulses of \pm 1 nA were applied. Horizontal dotted lines indicate the control amplitude. $C$, The coupling potential produced by eighth nerve stimulation has a similar voltage dependence. Superimposed traces show the response at resting potential and during $\pm 0.5 \mathrm{nA}$ current pulses. In all cases the superimposed traces represent averages of 10 or more consecutive individual responses.

$-27.3 \%$ of the control in the de- and hyperpolarizing directions, respectively. Voltage sensitivity could also be observed for the 8th nerve coupling potential (Fig. 4C). In this experimental series the input resistance of the afferents averaged 6.1 $\mathrm{M} \Omega$ (SEM $\pm 0.95, n=6$ ), which is comparable to results of a earlier study (Lin and Faber. 1988a). Thus, the voltage dependence was manifest with shifts in membrane potential of only $2.5-5 \mathrm{mV}$. Both the input resistance and the voltage sensitivity were similar for afferents penetrated in the nerve root or the brain.

The above results indicate that, as expected, club endings are coupled to each other via the M-cell and that the coupling coefficients are voltage dependent. These conclusions were confirmed by obtaining simultaneous intra-axonal recordings from afferent pairs. In the experiment of Figure 5 recordings were first obtained from one afferent in the nerve and the lateral dendrite, and the presynaptic spike produced a $1.2 \mathrm{mV}$ coupling potential in the dendrite. Then, the medullary electrode was moved to a presynaptic terminal, and the coupling coefficient was about half that observed in the dendrite (B). In addition, this coupling potential exhibited a strong and asymmetric voltage dependence, increasing by $112 \%$ with depolarization of the fiber, and decreasing by $67 \%$ with hyperpolarization.

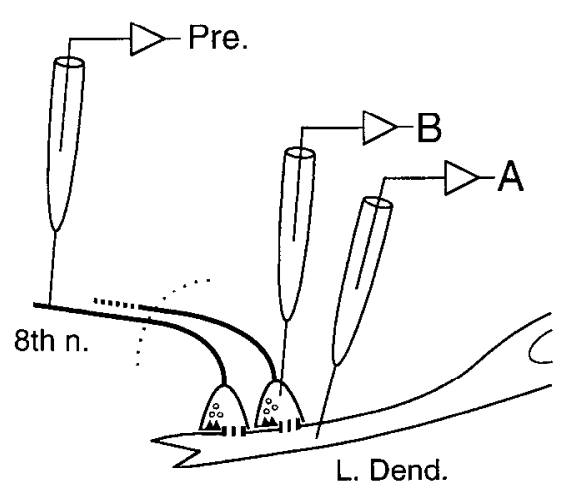

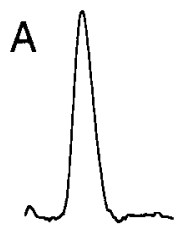

B
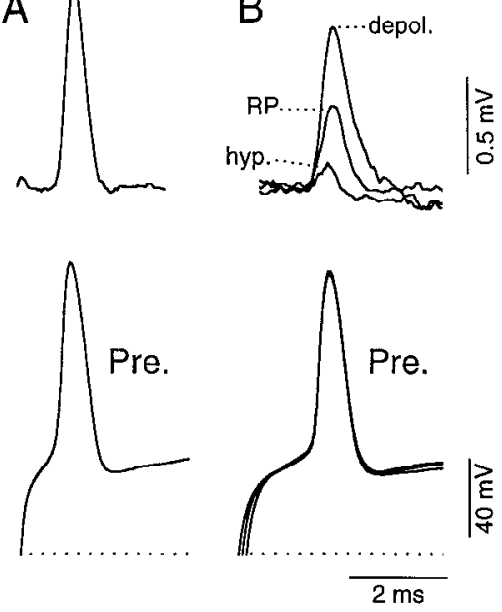

The results of Figures 4 and 5 indicate that the voltage dependence of the coupling potential is asymmetric, and this phenomena was then studied quantitatively, by comparing the waveforms of coupling potentials recorded at different membrane potentials. Figure $6 \mathrm{~A}$ illustrates another example in which the magnitude of the change in the coupling potential was more pronounced with presynaptic depolarization than with hyperpolarization. In the records of $\mathrm{A} 1$, the coupling potential was increased by $200 \%$ during the application of a steady $2.7 \mathrm{nA}$ depolarizing current, while it was only halved by the same current of opposite polarity. This differential is more clearly demonstrated in Figure 6A2, where the control coupling potential is compared with the difference waveforms associated with the two polarizations. These comparisons show that while the time course of the difference waveform was similar to that of the control in the case of hyperpolarization, depolarization added a response with different kinetics, in that its peak time was increased significantly. In a set of nine fibers where the effects of current injections of the same magnitudes but opposite polarities were quantified, the changes averaged $113.02 \%$ ( $\pm 18.4 \%$, SEM) of control for depolarizing current and $-40.16 \%$ ( $\pm 5.4 \%$, SEM) for the hyperpolarization. The ratio of the voltage dependencies 

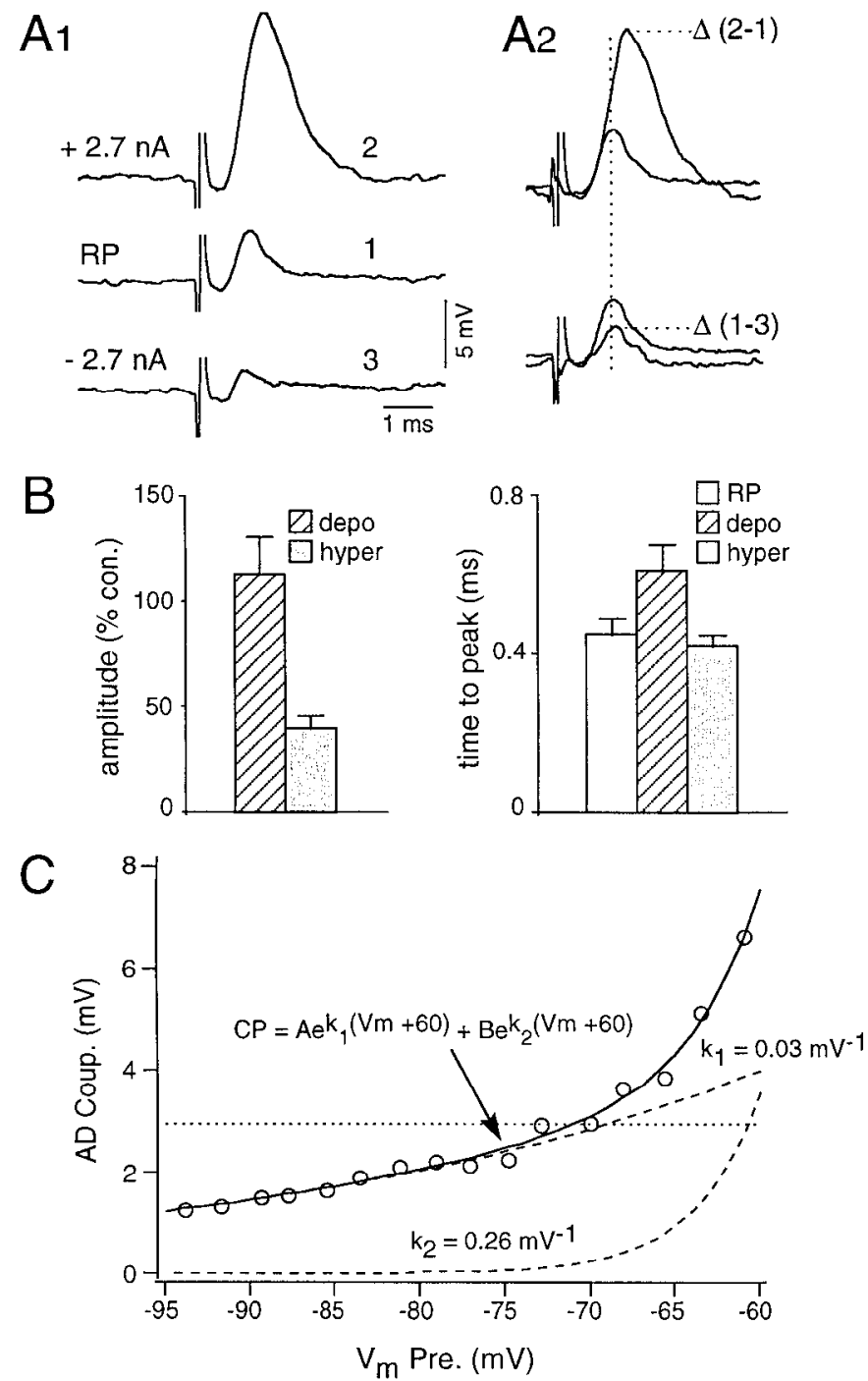

Figure 6. Asymmetric voltage dependence of coupling from the lateral dendrite to eighth nerve afferents. Al, Antidromic coupling potential recorded in one afferent at a resting potential of $-68 \mathrm{mV}(R P, l)$ and during the steady application of $+2.7 \mathrm{nA}(2)$ and $-2.7 \mathrm{nA}$ (3). Depolarization more than tripled the size of the coupling potential, while a comparable hyperpolarization only reduced it by about $45 \%$. A2, Superposition of the control and difference waveforms $[\Delta,(2-1)$, and $\Delta(1-3)]$ associated with positive (upper) and negative (lower) currents, demonstrating the appreciably larger effect of depolarization $[\Delta(I-3)$ is inverted to facilitate comparison with the control]. Vertical dashed line is at the peak time of the control and illustrates the discrepancy between the kinetics of that response and the added potential introduced by depolarizing the fiber during the stimulation. Traces represent averages of 10 consecutive individual responses. $B$, Quantification of the asymmetry of the voltage dependence of the coupling potential in nine fibers where currents of the same magnitude but opposite polarity were applied. Left, Comparison of the mean magnitude of change of the amplitude of the coupling potential, expressed as a percentage of control, for depolarizing and hyperpolarizing currents of the same magnitude (the observed difference was statistically significant; $p \leq 0.005$ ). Right, Bar diagrams of the mean time to peak of the coupling potential obtained at resting potential $(R P)$ and during the injection of depolarizing (depo) and hyperpolarizing (hyper) currents. Time to peak at depolarized potentials was significantly increased $(p \leq 0.005$ ). Error bars denote the SEM. $C$. Quantitative relationship between the antidromic coupling potential ( $A D$ Coup.) and the presynaptic membrane potential $\left(V_{m}\right.$ Pre $)$, the latter calculated on the assumption of an accurate bridge balance. The resting potential $(R P)$ in this case was $-70 \mathrm{mV}$. The data (open circles) were fitted with a double exponential function $\left(C P=A e^{k_{1}\left(V_{m}+60\right)}+B e^{k_{2}\left(V_{m}+60\right)}\right)$, shown with the solid line, and the two exponentials are also plotted (dotted lines) alone $\left(k_{1}, k_{2}\right)$. Horizontal dotted line represents the expected behavior if coupling potential was not voltage dependent. in the two directions ( $\Delta \%$ depolarization $/ \Delta \%$ hyperpolarization) was 2.8 , with the difference between the effects being statistically significant ( $p \leq 0.005$ ). The time to peak in the same set of experiments averaged $0.45 \mathrm{msec}( \pm 0.04, \mathrm{SEM})$ at resting potential, 0.42 ( \pm 0.03, SEM) during hyperpolarization, and 0.63 msec $( \pm 0.07, \mathrm{SEM})$ with depolarization. Again, the rise time obtained during depolarization was statistically different from that obtained in the other two conditions $(p \leq 0.005)$. These results are summarized in the histograms of Figure $6 B$.

Since this asymmetry of magnitude and kinetics suggests more than one mechanism might contribute to the observed voltage dependence, we examined the relationship between the AD coupling potential amplitude and presynaptic membrane potential in detail. Figure $6 C$ demonstrates graphically that the slope of this relationship increases sharply with depolarization (horizontal dotted line represents the expected behavior if the coupling coefficient was not voltage dependent). The data were then fit with a double exponential (continuous line) according to the expression

$$
C P=A e^{k_{1}\left(V_{m i}+60\right)}+B e^{k_{2}\left(V_{m i}+60\right)},
$$

where $C P$ is the coupling potential amplitude and $V_{m}$ the value of the membrane potential. The form of this relationship, particularly the $60 \mathrm{mV}$ offset, was established empirically and it was superior to a single exponential ( $r^{2}$ values were 0.777 and 0.999 for the single and double exponentials, respectively), even when the offset voltage was allowed to vary as part of the fitting procedure. Two very different voltage rate constants, -0.03 and $-0.26 \mathrm{mV}^{-1}\left(k_{1}\right.$ and $\left.k_{2}\right)$ were obtained, and the two exponentials are plotted as functions of the resting potential in the same figure (dotted lines). Interestingly, the steep voltage constant $\left(k_{2}\right)$ suggests the existence of a mechanism which is only activated when membrane potential is depolarized. A second mechanism is represented by a lower and relatively linear sensitivity to voltage in the vicinity of the resting potential.

\section{Nonlinear membrane properties of afferents and gap junctions}

There are three main potential sources of this apparent voltage dependence of coupling. One is a true voltage dependence of the junctional conductance itself; that is, junctional conductance might increase when the afferent is depolarized directly (junctional current flowing from the fiber to the lateral dendrite) and decrease when the direction of flow is reversed (see, Fig. 7A). Another possibility is a nonlinear subthreshold voltage sensitive conductance in the terminal membrane (Rce in Fig. 7A). Finally, although unlikely, it is necessary to consider the possibility that depolarization increases the antidromic action potential amplitude in the dendrite, for example by increasing dendritic input resistance (Rmc in Fig. 7A). This last mechanism could be ruled out in experiments where simultaneous recordings were obtained from the pre- and postsynaptic cells. Figure $7 B 1-B 3$ shows that a presynaptic depolarizing current pulse $(+1.2 \mathrm{nA})$ had no effect on the antidromic spike recorded in the dendrite (B2) while it markedly increased the coupling potential it produced in the fiher (B3)

To test the first possibility, the membrane properties of the afferents were examined by measuring their current-voltage relations without superimposed coupling potentials. The membrane responses to current steps were similar in three studied fibers, and one set of those responses is illustrated in Figure 8. For a given sized depolarizing current pulse, we found a non- 
A
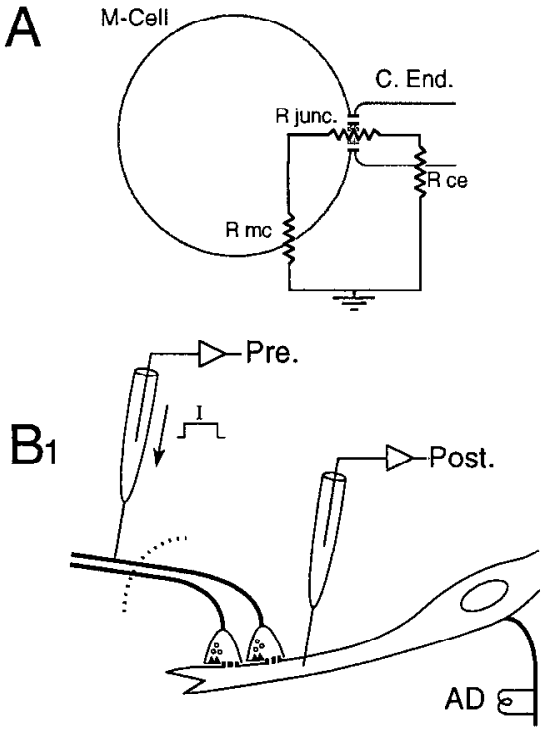

$\mathrm{B}_{2}$

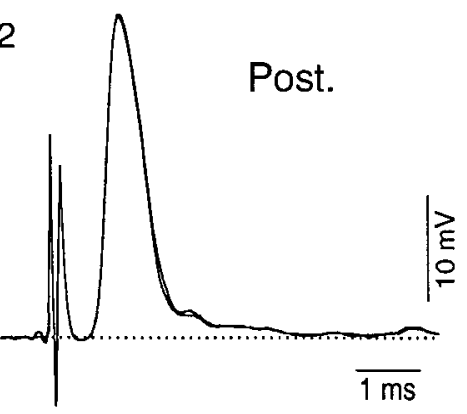

$\mathrm{B} 3$

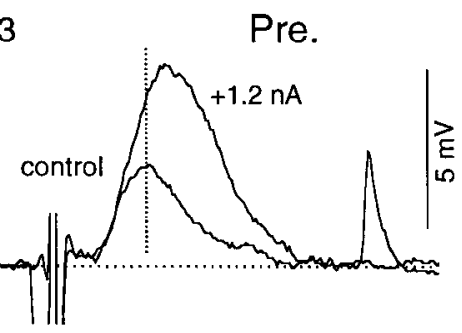

Figure 7. Apparent voltage dependence of coupling is not due to active membrane properties of the M-cell. $A$, Equivalent circuit with superimposed representation of the M-cell and a club ending ( $C$. End.) showing that the observed voltage dependence could reflect modification of any of three resistances: (1) that of the presynaptic fiber itself $(R c e)$, (2) the junctional resistance $(R$ junc.), and (3) the dendritic input resistance $(R m c)$. B. Demonstration that changes in Rmc are not involved, obtained with simultaneous recordings from the lateral dendrite and an afferent fiber $(B l) . B 2$, Superimposed records of the $\mathrm{M}$-cell antidromic spike obtained with and without a paired depolarization (1.2 nA) of the fiber. Note the absence of any effect on spike height (a measure of the M-cell's input resistance) in the dendrite. $B 3$, In contrast the applied current produced a dramatic effect on the antidromic coupling potential in the afferent. Note the increased time to peak of the enhanced response. linear voltage response which was maximal within $2 \mathrm{msec}$ and then rapidly decayed to a steady-state value. The magnitude of this initial response was proportional to the injected current (Fig. $8 A$, note that the response to the largest pulse reached threshold for spike initiation). As is illustrated in Figure $8 B$, the steadystate late response was a linear function of the polarizing current for de- and hyperpolarizing pulses, but the early responses exhibited the previously mentioned nonlinearity in the depolarizing direction, taking the form of an apparent increase in membrane slope resistance. The nonlinear component was isolated by taking the difference between the two $I / V$ plots (late minus initial or steady state voltages), and it is plotted in Figure $8 C$ against

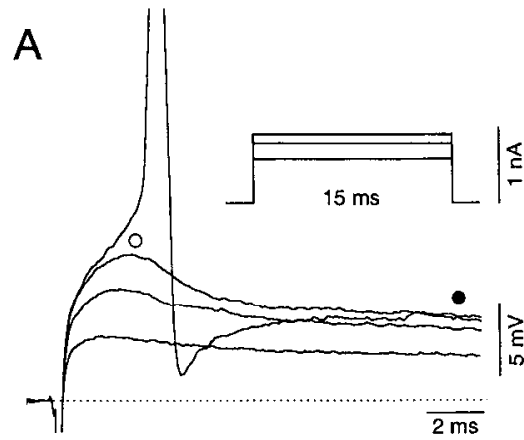

B

C
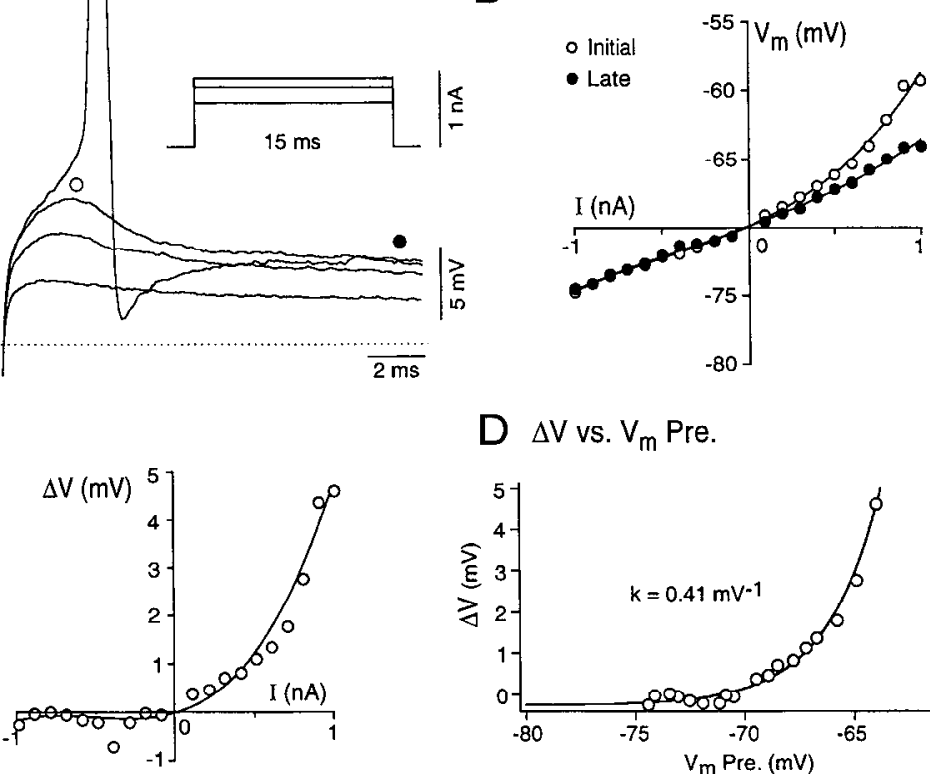

D $\Delta V$ vs. $V_{m}$ Pre.

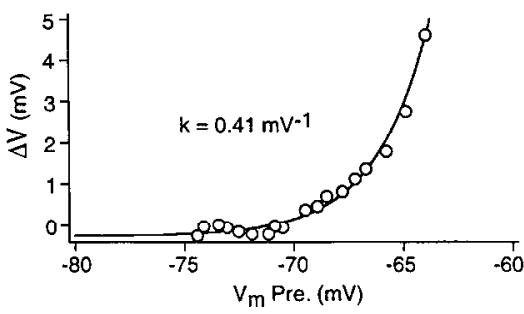

Figure 8. Nonlinear membrane properties of afferents contribute to the voltage dependence of antidromic coupling. A, Voltage responses to three current pulses (15 msec duration) of increasing magnitude $(0.6,0.8$, and $0.9 \mathrm{nA}$, inset). Note the progressively larger transient membrane response (O) at the pulse onset. Two responses to the $0.9 \mathrm{nA}$ depolarizing pulse are shown with one reaching the firing threshold for the fiber. $B$, Current $(I) /$ voltage $\left(V_{m}\right)$ relation obtained in the same afferent fiber, measured at 2 (open circles; see Fig. $7 \mathrm{~A}$ ) and 15 msec (solid circles). The $I-V$ relation is the same at both times for hyperpolarizations and the membrane behaves linearly in the steady state. However, at pulse onset the $I-V$ relationship exhibits a nonlinearity in the form of an apparent increase in membrane slope resistance with depolarization. $C$, Plot of the difference ( $\Delta \mathrm{V})$ between the two curves versus the magnitude of the polarizing current, illustrating the added response to depolarization. $D, \Delta \mathrm{V}$ replotted as a function of the afferent membrane potential $\left(V_{u}\right.$ pre. $)$, using the steady state value of the voltage response to the current pulses to determine $V_{m}$. The data are fit with a simple exponential function (solid curve) and the voltage constant $(k)$ is similar to the steep component of the fit obtained for antidromic coupling (Fig. $5 B, k_{1}$ ). 

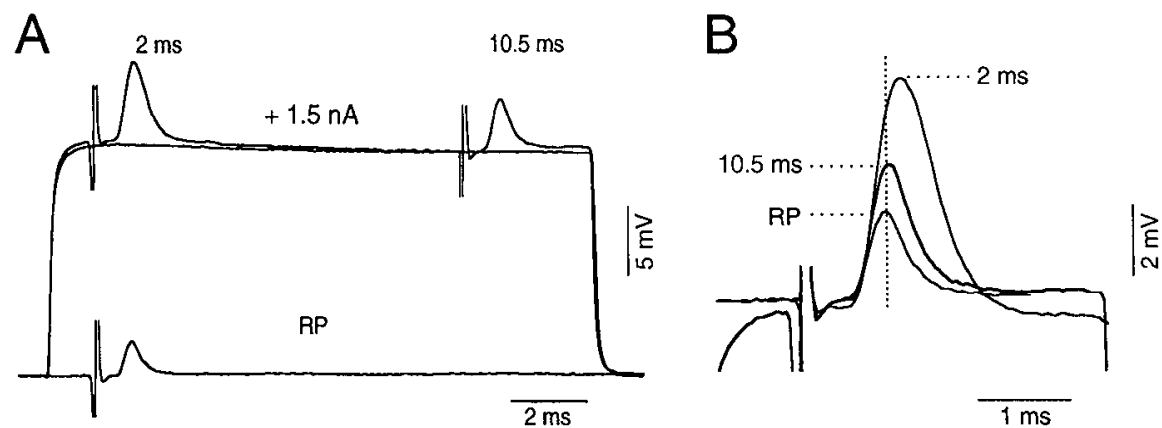

Figure 9. Temporal separation of the two factors contributing to voltage dependence of coupling. $A$ and $B$, Intracellular recordings of antidromic coupling potentials in an afferent. A, Superimposed records illustrating the coupling potential at resting potential $(R P=63 \mathrm{mV}$, lower trace $)$ and at 2 and $10.5 \mathrm{msec}$ after the onset of a $1.5 \mathrm{nA}$ depolarizing pulse. In this example, the electrode resistance was too high to permit accurate bridge balance. Note that the increase in coupling during the pulse is greatest at its onset. $B$, Superimposed records of the three coupling potentials, at higher gain and with an expanded time scale. The largest response, at $2 \mathrm{msec}$ after pulse onset, has a longer time to peak than the control or that at $10.5 \mathrm{msec}$ (dotted vertical line). All traces represent the average of 10 or more consecutive individual responses.

the magnitude of the injected current. As expected, this response was not activated when the afferent was hyperpolarized. To quantify the voltage sensitivity of this depolarization-induced response, it was also plotted against the membrane potential of the fiber, using the steady-state portion of the $I / \mathrm{N}$ relation, and then fit with an exponential function (Fig. $8 D$ ) by using the expression

$$
\Delta V=e^{k_{1}\left(V_{m}+60\right)}
$$

The voltage rate constant was $0.41 \mathrm{mV}^{-1}$ in the example of Figure 8 , and 0.28 and $0.58 \mathrm{mV}^{-1}$ in the other two experiments; thus, its average value, $0.42 \mathrm{mV}^{-1}$, is comparable to that obtained for the steep component of the voltage dependence of the antidromic coupling potential (Fig. 6C, $k_{2}$ ).

These findings suggest that a nonlinear presynaptic membrane property accounts for most of the changes in the antidromic coupling potential with afferent depolarization, but it cannot underlie the voltage dependence observed when the membrane potential is hyperpolarized. Further evidence for a dual mechanism was obtained by taking advantage of the kinetics of the voltage activated response. As shown in Figure $8 A$, this response inactivates rapidly, with a mean time constant of $2.3 \mathrm{msec}( \pm 0.3$ msec, SEM; $n=13$ ). Therefore, the contribution of the voltageactivated response of the afferent to the coupling potential should be greater at the beginning of a depolarization than after $10 \mathrm{msec}$. This was found to be the case in all the examined recordings. Furthermore, as illustrated in Figure $9 \mathrm{~A}$, there still is an increased coupling potential $10 \mathrm{msec}$ after the pulse onset, that is, when the fiber membrane behaves linearly for small potential changes. In addition, the waveforms of the control coupling potential and that at $10.5 \mathrm{msec}$ are similar, while the even larger response at $2 \mathrm{msec}$ after pulse onset has the longer rise time described above (Fig. $9 B$ ). Thus, there is a second voltage dependent process that becomes apparent as the nonlinear membrane response inactivates.

\section{Retrograde dye coupling}

We explored the possibility that a small molecular weight dye injected postsynaptically might diffuse into the presynaptic terminals. Retrograde dye coupling between the M-cell lateral dendrite and eighth nerve afferents, not demonstrated previously, is illustrated in Figure 10. For this experiment, the fluorescent dye Lucifer yellow (Stewart, 1978), a small molecular weight (457 $\mathrm{kDa}$ ) dye normally used to trace coupled cells, was pressure injected into the postsynaptic M-cell through the recording electrode $(n=2)$. With standard fluorescent microscopy, numerous long processes seemed to issue from the lateral dendrite, which is the region where the club endings are segregated. Examination of the distal part of the lateral dendrite with confocal microscopy revealed dye in small processes that, given their localization and size (Nakajima, 1974) most likely correspond to terminals of large myelinated club endings (Fig. 10, upper, arrowheads). Identification of the afferents and the dendritic region on which they terminated was confirmed with Nomarski optics (Fig. 10, lower). Note the characteristic curvature of the fibers as they approach the dendrite.

Further evidence for the existence of retrograde coupling arises from an experiment in which the dye Neurobiotin was injected intradendritically. Since this compound has a lower molecular weight $(322.8 \mathrm{kDa}$ ) than Lucifer yellow, it is believed to be a more sensitive indicator of gap junctional coupling (Kandler and Katz, 1995). Indeed, the junctions were quite permeable to Neurobiotin, as illustrated in Figure 11, which demonstrates that it spread to numerous afferent fibers.

\section{Discussion}

According to Ramon y Cajal's "principle of dynamic polarization" (Ramon y Cajal, 1911) synapses are thought to convey information in one direction. That is, information flows only from the presynaptic to the postsynaptic cell. However, bidirectionality is considered to be one of the most distinctive proper-

Figure 10. Retrograde dye coupling between the M-cell lateral dendrite and eighth nerve fibers which presumably correspond to large myelinated club endings. Upper, Confocal image ( $\mathrm{Z}$ section) of the distal portion of the lateral dendrite (about $500 \mu \mathrm{m}$ lateral to the initial segment) of a Lucifer yellow injected M-cell showing eighth nerve afferents (arrowheads) filled by dye that crossed gap junctions. Arrow indicates a larger dendritic branch. Lower, Photomicrograph obtained from the same region with Nomarski optics and showing club endings (asterisk) impinging on the dendrite. Scale bars: upper, $35 \mu \mathrm{m}$; lower, $20 \mu \mathrm{m}$. 

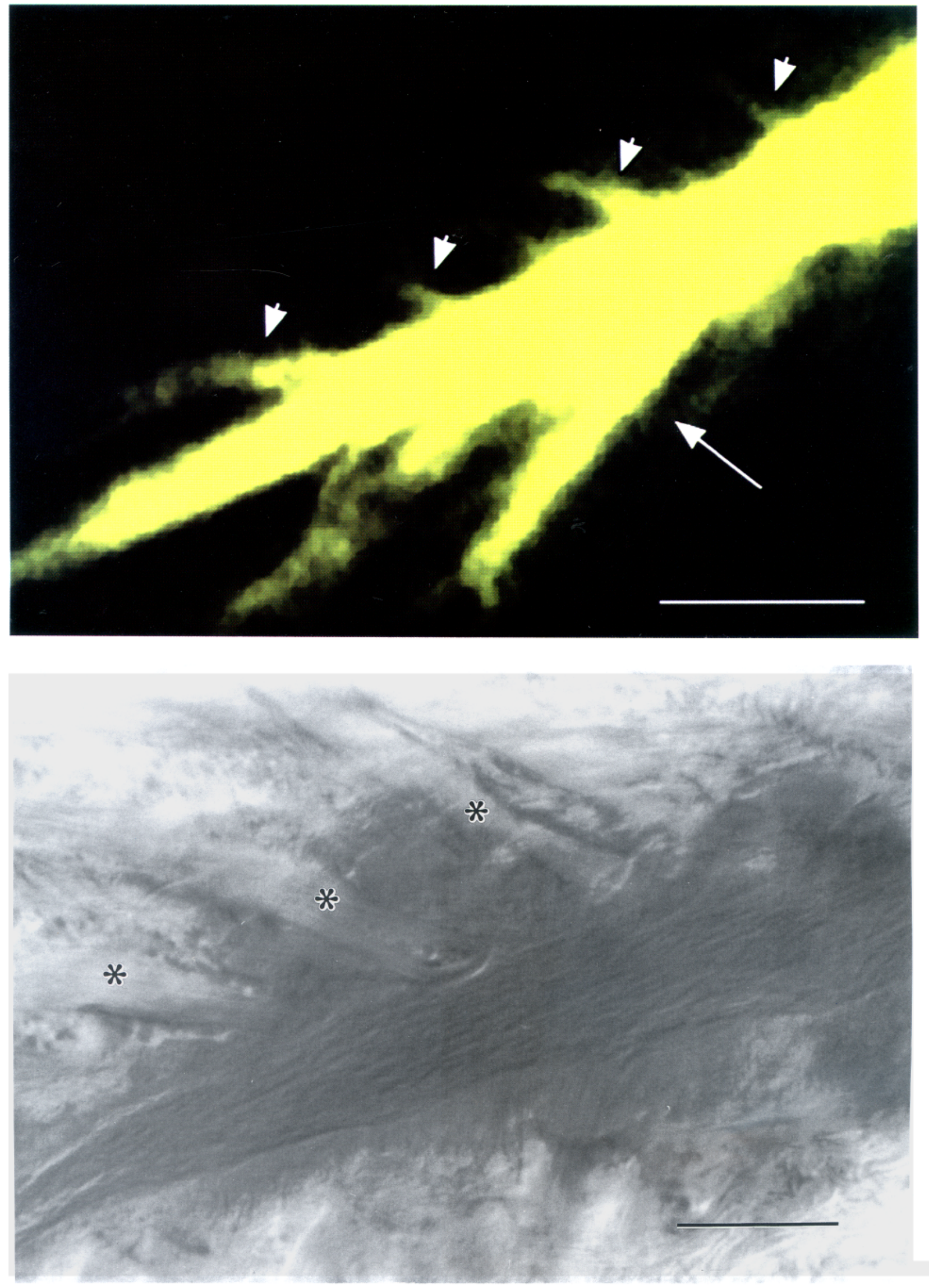


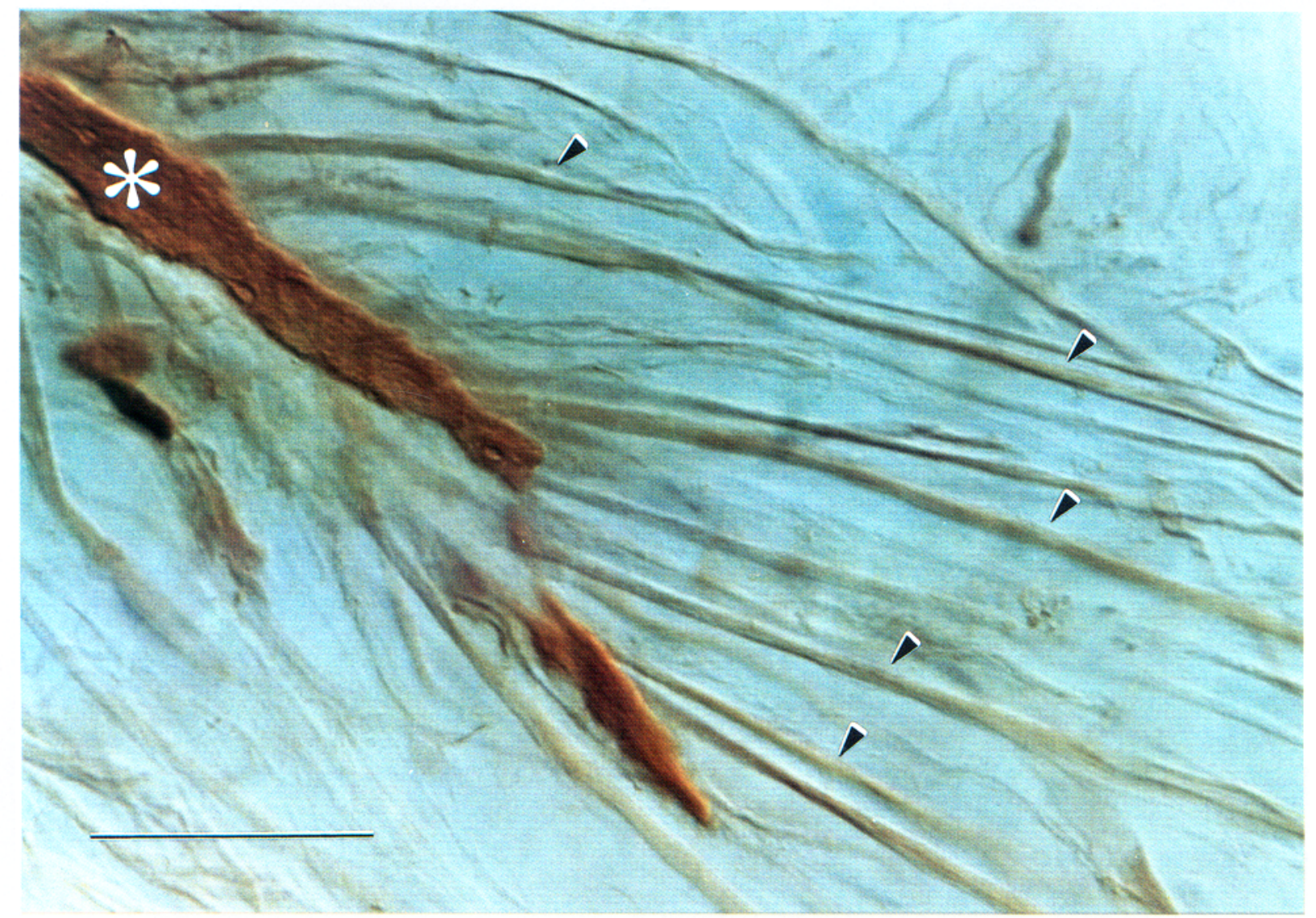

Figure 11. Retrograde staining of eighth nerve fibers with Neurobiotin injected in the M-cell lateral dendrite. Micrograph, obtained with Nomarski optics, shows the distal portion of the lateral dendrite (asterisk) of a Neurobiotin injected M-cell, and eighth nerve afferents (arrowheads) filled by diffusion of the dye across gap junctions. Scale bar, $50 \mu \mathrm{m}$.

ties of transmission at electrotonic synapses (Bennett, 1977). Coincidentally, there is now clear evidence for bidirectionality at chemical junctions so that information is also transmitted retrogradely from the target cell to the nerve terminal, albeit on a slow time scale, for example, during synapse formation (Jessel and Kandel, 1993; Lo et al., 1994) and for the long term control of synaptic efficacy (Schuman and Madison, 1991; Williams et al., 1993). The gap junctions present at large myelinated club endings are not only involved in fast anterograde synaptic transmission (Furshpan, 1964; Lin and Faber, 1988a; Yang et al., 1990; Pereda et al., 1992), but coupling in the reverse direction is strong enough to support backfiring of the afferents.

\section{Backfiring of afferent fibers}

The results demonstrate that the passive spread of currents originated postsynaptically can influence the excitability of presynaptic fibers. Consequently, the synaptic potential produced by activation of part of the afferent population can depolarize neighboring afferents and bring them to threshold, thereby providing a mechanism for synchronizing and modulating the activity of the afferent population. Direct evidence for backfiring was obtained by showing that action potentials could be elicited in individual afferents by: (1) a large coupling potential produced by the eighth nerve mixed EPSP, (2) superimposing two responses of postsynaptic origin, and (3) pairing a coupling potential with presynaptic depolarization. Indirect evidence for backfiring includes the variable latency of the eighth nerve evoked action potential in a given fiber and "spikelets" super- imposed on the chemical component of the large mixed synaptic responses in the dendrite. These "spikelets" are similar to those observed in other neurons and interpreted as representing active all-or-none events generated in neighboring coupled cells (Llinas et al., 1974; MacVicar and Dudek, 1982; Nuñez et al., 1990), although it is often difficult to distinguish this explanation from the alternative of remote dendritic impulses. In this case, the recordings were dendritic, time course of the spikelets resembles that of unitary coupling potentials (Lin and Faber, 1988a; see Fig. $1 B$ ), and their amplitudes are small. Hence, they probably represent backfiring of one or more afferent fibers.

Several anatomical and physiological characteristics of this system favor backfiring of the large myelinated club endings. They are electrically coupled to a restricted region of the M-cell's lateral dendrite, suggesting that dendritic depolarizations produced by the synchronous activation of part of the afferent population can spread to inactive neighboring contacts without appreciable attenuation due to dendritic filtering. Also, these afferents lose their myelin sheath near the terminal, indicating that the last heminode, which may support active spike initiation, is near the terminal ending (Nakajima, 1974). Finally, physiological properties of the afferents and the gap junctions confer a voltage dependence that favors backfiring and may, therefore, impart input specificity to this process.

\section{Voltage dependence of afferents}

Probably the most remarkable finding is that while in some systems junctional properties prevent the antidromic spread of those 
postsynaptically originated currents (Furshpan and Potter, 1964; Auerbach and Bennett, 1969: Ringham, 1975), physiological properties of the afferents and the gap junctions actually promote this phenomenon. Our analysis indicate that two mechanisms, with different voltage sensitivities (rate constants, $k_{1}$ and $k_{2}$ ), are involved in the voltage dependence of coupling. The first is a nonlinear membrane property of the afferent fiber, which underlies the steep voltage dependence in the depolarizing direction and is also manifest as an apparent increase in membrane slope resistance in the eighth nerve fibers for depolarizations of 10 to $15 \mathrm{mV}$ or more. This paradoxical change in slope resistance resembles anomalous rectification (Kandel and Tauc, 1966), and it may be produced by an inward $\mathrm{Na}^{+}$(Hotson et al., 1979; Llinas and Sugimori, 1980; Stafstrom et al., 1982; French and Gage, 1985; MacVicar, 1985; Stafstrom et al., 1985) or $\mathrm{Ca}^{2+}$ (Schwindt and Crill, 1980; Benardo et al., 1982; Brown and Griffith, 1983) current that is activated by subthreshold membrane depolarizations, an outward $\mathrm{K}^{+}$current (Constanti and Galvan, 1983) active at the resting level and during hyperpolarization, but inactivated by depolarization, or by a combination of the two (for mixed cation $\mathrm{Na}^{+} / \mathrm{K}^{+}$inward currents see also Adams and Halliwell, 1982, and Halliwell and $\Lambda$ dams, 1982). Without voltage clamp, we cannot distinguish between these possibilities. However, involvement of calcium channels is unlikely: the depolarizations are below threshold for high-threshold voltage activated channels and the transient low-threshold T-type current known to be present in neurons activates at least one order of magnitude too slowly to account for this phenomenon (Coulter et al., 1989). In contrast, the rapid onset of this anomalous rectification is most comparable to that of a persistent $\mathrm{Na}^{+}$ current (Hotson et al., 1979; Llinas and Sugimori, 1980; French and Gage, 1985; Mac Vicar, 1985). In particular, it seems to be similar to that described for sensorimotor cortical neurons where a persistent $\mathrm{Na}^{+}$current also prolongs synaptically induced depolarizations (Stafstrom et al., 1982, 1985). Moreover, because of its fast onset this persistent $\mathrm{Na}^{+}$current could be activated during a single excitatory postsynaptic potential and could influence the subsequent voltage time course and cell excitability in a fashion similar to the voltage dependence of the coupling potential described here (Stafstrom et al., 1985). The rapid decay of the enhanced coupling is not inconsistent with the postulate of a persistent $\mathrm{Na}^{+}$current, as it is often mixed with slow outward $\mathrm{K}^{+}$currents that underlie the voltage decay observed with current-clamp recordings (Stafstrom et al., 1985; Honmou et al., 1994). This combination would explain the linear steady-state current-voltage relationship of the afferents, as would the alternative, a rapidly inactivating inward current. Also, persistent $\mathrm{Na}^{+}$currents have been reported to be present in sensory axons (Kocsis et al., 1983; Bowe et al., 1985; Honmou et al., 1994). However, this membrane property cannot explain the voltage dependence of coupling observed at hyperpolarized potentials.

The weaker voltage dependence, associated with the first rate constant $\left(k_{1}\right)$ most likely reflects a voltage dependent property of the junctional membrane per se, a result which contradicts our previous conclusion that the gap junctions are voltage insensitive (Lin and Faber, 1988a). An adequate study of the observed behavior would require simultaneous recordings under voltage-clamp conditions. Nevertheless, one possibility is that this nonlinearity of coupling is transjunctional in origin (Bennett and Verselis, 1992). For example, in the crayfish, fast rectification of electrical coupling from the lateral and medial giant axons to the motor giant axon (Furshpan and Potter, 1959) is due to a transjunctional voltage dependence maintained by a difference between the resting potentials of the involved cells (postsynaptic side more depolarized; Giaume and Korn, 1983). There is also a comparable difference between the resting potentials of the club endings $(\sim-70 \mathrm{mV})$ cells and the dendrite $(\sim-83$ $\mathrm{mV}$ ). That is, the postsynaptic cell is more hyperpolarized in this case. However, in contrast with crayfish, coupling is enhanced by an increase in the transjunctional voltage difference. This distinction could be explained by differences in the properties of the involved connexins, the family of proteins that form the junctional channels. While homotypic connexin 43 junctions (the candidate connexin in this case; Yox et al., 1990) expressed in oocytes, have a weak transjunctional voltage dependence (Rook et al., 1988), those formed between connexin 43 and 38 exhibit pronounced rectification (Bennett and Verselis, 1992). That is, coupling of cells expressing dissimilar connexins is one way to establish rectifying junctions (Barrio et al., 1991; Bennett and Verselis, 1992), and this could be the case in the M-cell system. However, the transjunctional voltage dependent changes studied thus far are not fast enough to account for the $<0.1$ msec changes at rectifying synapses and the mechanisms of this fast voltage dependence remain obscure.

Alternatively, our results could be attributed to an inside-outside voltage dependency, so that changes in the membrane potential of one cell alone, for example the club ending, could affect junctional conductance. This phenomenon has been described for, the giant salivary glands of dipterans (Verselis et al., 1991) and for oocytes that express homotypic connexin 26 junctions (Barrio et al., 1991) with the voltage sensitivity in the latter being in the same direction as that reported here.

\section{Functional significance}

There exist several reported examples of primary afferent excitation produced by postsynaptic activity. In fact, after it was established that synaptic transmission is generally chemical (Eccles, 1957; Grundfest, 1959), Fatt (1957) argued that structural relations are more favorable for electrical transmission in the antidromic than in the orthodromic direction, and this mecha nism was invoked to explain the centrifugal dorsal root response to ventral root stimulation (Decima, 1969). Moreover, this process is greatly facilitated in those cases where gap junctions in the synaptic endings provide a low resistance pathway for the spread of postsynaptic currents, as first demonstrated in the chick ciliary ganglion mixed synapse (Martin and Pilar, 1963). Backfiring of electrotonically coupled primary afferents has subsequently been shown in a number of lower vertebrates, including mormyromast afferents of Mormyrid electric fish (Zipser and Bennett, 1976; Slesinger and Bell, 1985) and vestibular afferents of the toadfish (Korn et al., 1977). In the first case it has been proposed that this mechanism may mediate a functionally relevant rapidly acting type of lateral inhibition (Slesinger and Bell, 1985) while in the second it was speculated that this backfiring provides a way of communication between neighboring coupled cells (Korn et al., 1977).

The retrograde communication presumably is not restricted to the spread of electrical currents, as Lucifer yellow and Neurobiotin were found in the terminals of eighth nerve fibers, most likely the large myelinated club endings, when injected postsynaptically into the M-cell. Thus, the gap junctions provide the substrate by which postsynaptic messengers can diffuse to the presynaptic terminal to modulate its function. Retrograde signaling via the extracellular space has been postulated to play an 


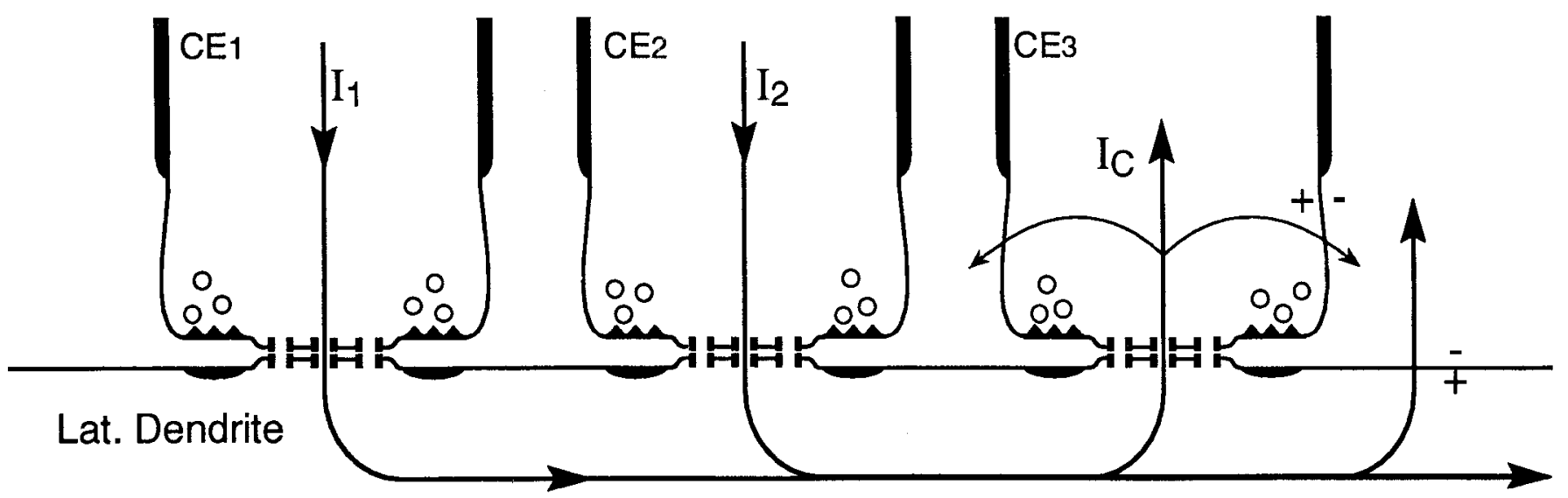

Figure 12. Scheme for coupling of afferents through the M-cell lateral (Lat.) dendrite. The eighth nerve saccular fibers are segregated along the distal part of the M-cell's lateral dendrite, and the currents associated with impulses in two afferents (CE1, $C E 2)$ flow through gap junctions into the M-cell and back to a presynaptic afferent that is not active (CE3). The coupling current, $I_{c}$, depolarizes the inactive fiber and may be sufficient to activate it, either alone or in conjunction with a subthreshold input. This coupling potential may serve to synchronize afferent impulse activity and to "boost" synaptic activation of the M-cell by increasing the number of active fibers.

important role in the expression and maintenance of hippocampal long term potentiation (Schuman and Madison, 1991; Williams et al., 1993). Since long term modifications of the strength of the eighth nerve connection onto the M-cell can be elicited by either afferent activity (Yang et al., 1990) or by the action of modulatory neurotransmitters (Pereda et al., 1992, 1994), retrograde signaling, if involved, might also be mediated via gap junctions in this case.

In conclusion large myelinated club endings are electrically coupled to each other through the M-cell's lateral dendrite (Fig. 12). Such coupling may enhance the effectiveness of this input when only some fibers are active, by synchronizing that afferent population, and promoting the recruitment of new fibers by backfiring those that are close to threshold. This "cooperativity" could introduce significant nonlinearities to the input-output relationship between the eighth nerve and the lateral dendrite. To distinguish this effect from the typical nonlinear input-output relation for a nerve with different sized fibers would require simultancous recordings of the presynaptic volley and the postsynaptic responses. It is interesting however, that the potentiations of both components of the synaptic response produced by either the application of dopamine (Pereda et al., 1992) or afferent tetanization (X. D. Yang, personal communication) are greater for weak test stimuli than for stronger ones, a phenomenon which could be explained by postulating that with the weak test more fibers could eventually be recruited by backfiring, thereby boosting the amplitude of the synaptic enhancement. Thus, gap junctions would seem to be a good target for mediating long-term changes in the synaptic effectiveness of an afferent population.

\section{References}

Adams P, Halliwell JV (1982) A hyperpolarization-induced inward current in hippocampal pyramidal cells. J Physiol (Lond) 324:62-63.

Auerbach AA, Bennett MVL (1969) A rectifying synapse in the central nervous system of a vertebrate. J Gen Physiol 53:183-210.

Barrio L, Schuyna T, Bargiello TA, Xian Hu L, Roginski R, Bennett MVL, Nicholson B (1991) Gap junctions formed by connexin 26 and 32 alone and in combination are differently affected by applied voltage. Proc Natl Acad Sci USA 88:8410-8414.

Baylor DA, Nicholls JG (1969) Chemical and electrical synaptic connections between cutaneous mechanoreceptor neurones in the central nervous system of the leech. J Physiol (Lond) 203:591-609.
Benardo LS, Masukawa LM, Prince D (1982) Electrophysiology of isolated hippocampal pyramidal dendrites. J Neurosci 2:1614-1622.

Bennett MVL (1977) Electrical transmission: a functional analysis and comparison with chemical transmission. In: Handbook of physiology, Vol I, Sect I, Cellular biology of neurons, The nervous system (Kandel ER, ed), pp 357-416. Baltimore: Williams and Wilkins.

Bennett MVL, Verselis VK (1992) Biophysics of gap junctions. Sem Cell Biol 3:29-47.

Bennett MVL, Pappas G, Gimenez M, Nakajima Y (1967) Physiology and ultrastructure of electrotonic junctions. IV. Medullary electromotor nuclei in gymnotid fish. J Neurophysiol 30:236-300.

Bennett MVL, Barrio LC, Bargiello TA, Spray DC, Hertzberg E, Saéz JC (1991) Gap junctions: new tools, new answers, new questions. Neuron 6:305-320.

Bowe CM, Kocsis JD, Waxman SG (1985) Differences between mammalian ventral and dorsal spinal roots in response to blockade of potassium channels during maturation. Proc R Soc Lond [Biol] Sci 224:355-366.

Brown DA, Griffith WH (1983) Persistent slow inward calcium current in voltage-clamped hippocampal neurones of the guinea-pig. J Physiol (Lond) 337:303-320.

Constanti A, Galvan M (1983) Fast inward-rectifying current accounts for anomalous rectification in olfactory cortex neurons. I Physiol (Lond) 385:153-178.

Coulter D, Huguenard J, Prince D (1989) Calcium currents in rat thalamocortical relay ncurons: kinetic properties of the transient, lowthreshold current. J Physiol (Lond) 414:587-604.

Décima EE (1969) An effect of postsynaptic neurons upon presynaptic terminals. Proc Natl Acad Sci USA 63:58-64.

Eaton RC, Di Domenico R, Nissanov J (1991) Role of the Mauthner cell in sensorimotor integration by the brain stem escape network. Brain Behav Evol 37:272-285.

Eccles JC (1957) The physiology of the nerve cell. Baltimore: Johns Hopkins UP.

Faber DS, Korn H (1978) Electrophysiology of the Mauthner cell: basic properties, synaptic mechanisms, and associated networks. In: Neurobiology of the Mauthner cell (Faber DS, Korn H, eds), pp 47132. New York: Raven.

Faber DS, Korn H (1986) Instantaneous inward rectification in the Mauthner cell: a postsynaptic booster for excitatory inputs. Neuroscience 19:1037-1043.

Fatt P (1954) Biophysics of junctional transmission. Physiol Rev 34: 6/4-110.

French CR, Gage PW (1985) A threshold sodium current in pyramidal cells in rat hippocampus. Neurosc Lett 56:289-293.

Furshpan EJ (1964) Electrical transmission at an excitatory synapse in a vertebrate brain. Science 144:878-880.

Furshpan EJ, Furukawa $T$ (1962) Intracellular and extracellular responses of the several regions of the Mauthner cell of the goldfish. J Physiol (Lond) 25:732-771. 
Furshpan EJ, Potter DD (1959) Transmission at the giant motor synapses of the crayfish. J Physiol (Lond) 145:289-325.

Giaume C, Korn H (1983) Bi-directional transmission at the rectifying electrotonic synapse: a voltage-dependent process. Science 220:8487.

Grundfest H (1959) Synaptic and ephaptic transmission. In: Handbook of physiology, Vol I, Sect I, Neurophysiology (Ficld J, cd), pp 147197. Baltimore: Williams and Wilkins.

Halliwell JV, Adams P (1982) Voltage clamp analysis of muscarinic excitation in hippocampal neurons. Brain Res 250:71-92.

Heitler WJ, Fraser K, Edwards DH (1991) Different types of rectification at electrical synapses made by a single crayfish neurone investigated experimentally and by computer simulation. J Comp Physiol 169:707-718.

Honmou O, Utzschneider D, Rizzo M, Bowe C, Waxman SG, Kocsis JD (1994) Delayed depolarization and slow sodium currents in cutaneous afferents. J Neurophysiol 71:1627-1637.

Hotson JR, Prince DA, Schwartzkroin PA (1979) Anomalous inward rectification in hippocampal neurons. J Neurophysiol 42:889-895.

Jessel TM, Kandel E (1993) Synaptic transmission: a bi-directional and self-modifiable form of cell-cell communication. Cell $72 /$ Neuron 10(Suppl): $1-30$.

Kandel E, Tauc L (1966) Anomalous rectification in the metacerebral giant cells and its consequence for synaptic transmission. J Physiol (Lond) 183:287-304.

Kandler K, Katz LC (1995) Neuronal coupling and uncoupling in the developing nervous system. Curr Opin Neurobiol 5:98-105.

Kocsis J, Waxman SG (1983) Long-term regenerated nerve fibers retain sensitivity to potassium channel blocking agents. Nature 304 : 640-642.

Korn H, Bennett MVL (1975) Vestibular nystagmus and teleost oculomotor neurons: functions of electrotonic coupling and dendritic impulse initiation. J Neurophysiol 38:430-451.

Korn H, Faber DS (1979) Electrical interactions between vertebrate neurons: fields effects and electrotonic coupling. In: The neurosciences 4th study program (Schmitt FO, Worden FG, eds), pp $333-$ 358. Cambridge, MA: MIT Press.

Korn H, Sotelo C, Bennett MVL (1977) The lateral vestibular nucleus of the toadfish Opsanus tau: ultrastructural and electrophysiological observations with special reference to electrotonic transmission. Neuroscience 2:851-884.

Kriebel M, Bennett MVL, Waxman S, Pappas G (1969) Oculomotor neurons in fish: electrotonic coupling and multiple sites of impulse initiation. Science 166:520-523

Lin JW, Faber DS (1988a) Synaptic transmission mediated by single club endings on the goldfish Mauthner cell. I. Characteristics of electrotonic and chemical postsynaptic potentials. J Neurosci 8:13021312.

Lin JW, Faber DS (1988b) An efferent inhibition of auditory afferents mediated by the goldfish Mauthner cell. Neuroscience 24:829-836.

Llinás R, Sugimori M (1980) Electrophysiological properties of in vitro Purkinje cell somata in mammalian cerebellar slices. J Physiol (Lond) 305:171-195.

Llinás R, Baker R, Sotelo C (1974) Electrotonic coupling between neurons in the cat inferior olive. J Neurophysiol 37:560-571.

Lo Y, Lin Y, Sanes D, Poo M (1994) Depression of developing neuromuscular synapses induced by repetitive postsynaptic depolarization. J Neurosci 14:4964-4704.

Mac Vicar B (1985) Depolarizing prepotentials are $\mathrm{Na}^{+}$dependent in CAl pyramidal neurons. Brain Res 333:378-381.

MacVicar B, Dudek FE (1982) Electrotonic coupling between granule cells of rat dentate gyrus: physiological and anatomical evidence. J Neurophysiol 47:579-592.
Martin AR, Pilar G (1963) Dual mode of synaptic transmission in the avian ciliary ganglion. J Physiol (Lond) 168:443-463.

Nakajima Y (1974) Fine structure of the synaptic endings on the Mauthner cell of the goldfish. J Comp Neurol 156:375-402.

Nuñez A, García-Austt E, Buño W (1990) In vivo electrophysiological analysis of Lucifer yellow-coupled hippocampal pyramids. Exp Neurol 108:76-82.

Pereda A, Triller A, Korn H, Faber DS (1992) Dopamine enhances both electrotonic coupling and chemical excitatory postsynaptic potentials at mixed synapses. Proc Natl Acad Sci USA 89:1208812092

Pereda A, Nairn A, Wolzson L, Faber DS (1994) Postsynaptic modulation of synaptic efficacy at mixed synapses on the Mauthner cell. J Neurosci 14:3704-3712.

Ramon y Cajal SR (1911) Histologie du systeme nerveux de l'homme et des vertébrés. Paris: Maloine [republished in 1955 as Histologie du systeme nerveux. Translated by L Azoulay (Madrid, Instituto Ramón y Cajal)].

Ringham GL (1975) Localization and electrical characteristics of a giant synapse in the spinal cord of the lamprey. J Physiol (Lond) 251: 395-407.

Rook MB, Jongsma HJ, van Ginnneken AC (1988) Properties of single gap junctions channels between isolated neonatal rat heart cells. Am J Physiol 255:H770-H782.

Schumann EM, Madison DV (1991) A requirement for the intracellular messenger nitric oxide in long-term potentiation. Science 254:15031506.

Schwindt PC, Crill WE (1980) Effects of barium on cat spinal motoneurons studied by voltage clamp. J Neurophysiol 44:827-846.

Shapovalov AI (1980) Interneuronal synapses with electrical, dual and chemical mode of transmission in vertebrates. Neuroscience 5:11131124.

Slesinger P, Bell CC (1985) Primary afferent fibers conduct impulses in both directions under physiological stimulus conditions. J Comp Physiol 157:15-22.

Staftsrom CE, Schwindt PC, Crill WE (1982) Negative slope conductance due to a persistent subthreshold sodium current in cat neocortical neurons in vitro. Brain Res 236:221-226.

Staftsrom CE, Schwindt PC, Chubb MC, Crill WE (1985) Properties of a persistent sodium conductance and calcium conductance of layer $\mathrm{V}$ neurons from cat sensorimotor cortex in vitro. J Neurophysiol 53: $153-170$.

Stewart WW (1978) Functional connections between cells as revealed by dye-coupling with a highly fluorescent naphthalimide tracer. Cell 14:741-759.

Tuttle R, Masuko S, Nakajima Y (1986) Freeze fracture study of the large myelinated club ending synapse on the goldfish Mauthner cell: special reference to the quantitative analysis of gap junctions. J Comp Neurol 246:202-211.

Verselis VK, Bennett MVL, Bargiello TA (1991) A voltage dependent gap junction in Drosophila melanogaster. Biophys J 59:11-26.

Williams JH, Errington ML, Li Y-G, Lynch MA, Bliss TVP. The search for retrograde messengers in long term potentiation. Sem Neurosci 5:149-158

Wu SM (1994) Synaptic transmission in the outer retina. Annu Rev Physiol 56:141-168.

Yang XD, Korn H, Faber DS (1990) Long-term potentiation of electrotonic coupling at mixed synapses. Nature 348:542-545.

Yox DP, Faber DS, Nicholson BJ (1990) Gap-junction antibody attenuates electrical coupling between the goldfish Mauthner (M-) cell and its eighth nerve afferents. Soc Neurosci Abstr 16:185.

Zipser B, Bennett MVL (1976) Responses of cells of posterior lateral line lobe to activation of electroreceptors in a Mormyrid fish. J Neurophysiol 39:693-712. 